\title{
ATTRACTIVENESS OF THE DARK CENTRAL FLORET IN WILD CARROTS: DO UMBEL SIZE AND HEIGHT MATTER?
}

\author{
Victor H. Gonzalez ${ }^{*}$, Peter $\mathrm{Cruz}^{2}$, Nadiyah Folks³, Sarah Anderson ${ }^{4}$, Dillon Travis 5 ,John M. Hranitz ${ }^{6}, \&$ John \\ F. Barthell ${ }^{7}$
}

${ }^{1}$ Undergraduate Biology Program and Department of Ecology and Evolutionary Biology, Haworth Hall, 1200 Sunnyside Ave., University of Kansas, Lawrence, Kansas, 66045, USA

${ }^{2}$ Montclair State University, Montclair, New Jersey, 07043, USA

${ }^{3}$ University of Texas at El Paso, El Paso, Texas, 79902

${ }^{4}$ University of Kansas, Lawrence, Kansas, 66045, USA

${ }^{5}$ Boston University, Boston, Massachusetts, 02215, USA

${ }^{6}$ Biological and Allied Health Sciences, Bloomsburg University, Bloomsburg, PA, 17815, USA

${ }^{7}$ Department of Biology and Office of Provost \& Vice President for Academic Affairs, University of Central Oklahoma, Edmond, Oklahoma, 73034, USA

\begin{abstract}
The function of the dark central floret (DCF) in the wild carrot, Daucus carota L. (Apiaceae), is uncertain. It has been suggested that it is a vestigial structure without a function, that it serves as a long or short distance signal to attract pollinators, or that it might function as a defense mechanism against herbivores. We experimentally assessed the role of the umbel size and height in the attractiveness of the DCF to insects in a coastal population of $D$. carota in western Turkey. We did not find differences in the number of insect visits between umbels with a DCF and umbels in which the DCF was removed when they were of average diameter $(I 0 \mathrm{~cm})$ and were placed either at the average inflorescence height $(120 \mathrm{~cm})$ or at $I 47 \mathrm{~cm}$ above ground. Similarly, we did not find differences in the number of insect visits before and after the removal of the DCF from an umbel or between umbels of small (5$7 \mathrm{~cm}$ ) and large (II-I3 cm) diameters. However, umbels of average diameter with DCF received more insect visits than those without it when we placed them at $8 \mathrm{I} \mathrm{cm}$ above ground. These results suggest that umbel height, not diameter per se, influences the attractiveness of the DCF in the studied population. Thus, our study supports the hypothesis that DCF function depends on ecological context, reliant on both the visitor community and the predominant flower phenotype.
\end{abstract}

Keywords: Bees; Coleoptera; Diptera; Pollination; Turkey

\section{INTRODUCTION}

The wild carrot, Daucus carota L. (Apiaceae), is native to Europe, Asia and North Africa, and it has been introduced to North America, Australia, New Zealand, and South Africa (Lamborn \& Ollerton 2000). As in other umbellifers, the flowers of this species are in a compound inflorescence (umbel) at the end of a stem. Each umbel consists of many umbellets, which are composed of several individual florets. In $D$. carota, one or several of the florets in the central umbellet are pink or dark purple and thus stand out among the white florets of the remaining umbellets. The function of the dark central florets (DCF), which not only vary in numbers but also in their presence within a population, has been a matter of debate for many years. Some authors have suggested that the

Received 5 August 2017, accepted I5 May 2018

*Corresponding author: victorgonzab@gmail.com
DCF is a vestigial structure without a function (Darwin I888), that it serves as a long or short distance signal to attract or deter flower visitors, or that it might function as a defense mechanism against herbivores, such as the gall midge Kiefferia pericarpiicola (Bremi) (Diptera: Cecidomyiidae) (e.g., Eisikowitch 1980; Lamborn \& Ollerton 2000; Goulson et al. 2009; Polte \& Reinhold 2013).

Such a diversity of explanations attributed to the DCF appears to be a reflection of the generalized pollination system of $D$. carota, varying in function depending on the local pollinator availability and composition (Ollerton et al. 2007; Goulson et al. 2009; Polte \& Reinhold 2013). For example, the number of floral visitors recorded for $D$. carota ranges from 20 species in Europe to more than 300 species in North America. In addition, different taxa of floral visitors respond differently to the removal of the DCF among locations and even between years in the same population (e.g., Bohart \& Nye 1960; Westmoreland \& Muntan 1996; Lamborn \& Ollerton 2000; Goulson et al. 2009). 
The adaptive value of the DCF might also depend on other factors, such as the height and size of the umbel. In general, flowers or inflorescences of taller plants naturally attract more bees and other pollinators than those of short plants (e.g., Gumbert \& Kunze I999; Lortie \& Aarssen 1999), and large umbels tend to receive higher visitation rates than small umbels (Thomson 1988). In fact, Goulson et al. (2009) noted that adults of the dermestid beetle Anthrenus verbasci (Linnaeus) are more abundant in larger umbels of D. carota, as well as in umbels with greater numbers of dark florets.

Herein, we sought to answer the following questions: Does the DCF have a role in the attraction of floral visitors in a coastal population of D. carota in western Turkey? Do umbel size and height have a role in the attractiveness of the DCF to visitors?

\section{MATERIALS AND METHODS}

From June 2I to 27, 2016, we conducted observations on a coastal population of D. carota $\left(40^{\circ} 04^{\prime} 30.67^{\prime \prime} \mathrm{N}\right.$, 26ㅇ' $6^{\circ} 36.4 I^{\prime \prime}$ E, II m a.s.1.) located next to the Dardanos Dormitory at Çanakkale Onsekiz Mart University (ÇOMÜ) in the Republic of Turkey. Umbels ranged from 6.0 to 16.5 $\mathrm{cm}(\bar{x}=10.2 \pm 2.10, N=106)$ in diameter and from 64.8 to $211.2 \mathrm{~cm}(\bar{x}=126.6 \pm 29.7, N=106)$ in height, the latter measured from the ground to the base of the umbel. Umbel diameter was positively associated with height (Spearman's correlation, $r_{s}=0.283, P=0.003$ ). To explore the role of umbel size and height in the attractiveness of the DCF, we assessed insect visitation in the following four experiments (Table I), each of which controlled for one or both independent variables:

Experiment I. We compared umbels of average diameter $(10 \mathrm{~cm})$ placed at the average population's height $(120 \mathrm{~cm})$.

Experiment 2. We compared umbels of average diameter (I0 $\mathrm{cm}$ ) placed at $8 \mathrm{I}$ and $I 47 \mathrm{~cm}$ above the ground, representing heights below and above the average population's height.
Experiment 3. We compared small $(5-7 \mathrm{~cm})$ versus large (I I-I3 cm) umbels placed at the average population's height.

For experiments I-3, we set up one or two parallel transects $0.4-0.5 \mathrm{~m}$ apart. Along the transects, we established treatments using water picks (plastic tubes filled with water and covered with a rubber cap that has a hole in the center through which the flower stem is inserted). We tied pairs of water picks onto stems of plants, each 4-5 $\mathrm{m}$ apart along the length of the transect. The number of transects and pairs of water picks varied among experiments (Table I). In Experiment I, we set up a single transect consisting of $I 0$ pairs of water picks. In Experiment 2, we set up two transects, each consisting of five pairs of water picks, placed at alternated heights (five pairs at $8 \mathrm{I} \mathrm{cm}$, five pairs at $147 \mathrm{~cm}$ above the ground). In Experiment 3, we set up two transects, each consisting of six pairs of water picks.

About 30-40 minutes before we started the experiments, we placed umbels in the water picks and then randomly removed, with forceps, the DCF from one of the umbels (treatment) of each pair. The umbel with the intact DCF served as a control. In Experiment 3, we set up two additional types of pairs (Table I), one in which we left the DCF intact in both umbels (small and large) and one in which we removed the DCF from both of them, thus serving as positive and negative controls, respectively. Along a transect, we repeated each type of pair three times.

We selected undamaged umbels without galls. If spiders or beetles were present on the umbels, we removed them with forceps or a brush before we placed them in the water picks. We conducted Experiments I-3 for two days each and used a new umbel each time. Two observers recorded hourly insect visitation to umbel pairs, for $2.5 \mathrm{~min}$ at 10:00 through 14:00 hours, when activity was highest and before umbels began to wilt. To avoid disturbing insect visitors, we conducted observations about I $\mathrm{m}$ away from the umbels. We considered a visit only to be when insects landed directly on the umbels.

Table I. Summary of experiments conducted on a coastal population of Daucus carota L. in western Turkey. We completed Experiments I-3 on two days, each day using a new umbel, and Experiment 4 on the same day and same umbel, after the removal of the dark central floret. $-=$ not applicable, as the same umbel was compared before and after the removal of the DCF.

\begin{tabular}{|c|c|c|c|c|}
\hline Experiment & Description & Function & \#Transects & \# Pairs \\
\hline I & $\begin{array}{l}\text { Average size umbels }(10 \mathrm{~cm}) \text { at } \\
\text { average population height }(120 \mathrm{~cm})\end{array}$ & $\begin{array}{l}\text { Baseline } \\
\text { comparisons }\end{array}$ & I & IO \\
\hline 2 & $\begin{array}{l}\text { Average size umbels below }(8 \mathrm{Im}) \\
\text { and above }(\mathrm{I} 47 \mathrm{~cm}) \text { average } \\
\text { population height }(\mathrm{I} 20 \mathrm{~cm})\end{array}$ & $\begin{array}{l}\text { Testing effect of } \\
\text { height }\end{array}$ & 2 & $\begin{array}{l}5 \text { (below) } \\
5 \text { (above) }\end{array}$ \\
\hline 3 & $\begin{array}{l}\text { Umbel of small }(5-7 \mathrm{~cm}) \text { and large } \\
(\mathrm{I}-\mathrm{I} 3 \mathrm{~cm}) \text { diameters with }(\mathrm{W}) \\
\text { and without }(\mathrm{Wo}) \text { the dark central } \\
\text { floret }\end{array}$ & $\begin{array}{l}\text { Testing effect of } \\
\text { umbel diameter }\end{array}$ & 2 & $\begin{array}{l}3 \text { (small/W vs. large/W) } \\
3 \text { (small/W vs. large/Wo) } \\
3 \text { (small/Wo vs. large/W) } \\
3 \text { (small/Wo vs. large/Wo) }\end{array}$ \\
\hline 4 & $\begin{array}{l}\text { Average size umbels at average } \\
\text { population height; umbels not } \\
\text { removed from plants }(N=4 \mathrm{I})\end{array}$ & $\begin{array}{l}\text { Control for } \\
\text { possible } \\
\text { handling effects }\end{array}$ & I & - \\
\hline
\end{tabular}


If an insect moved from one to another umbel and returned to the original umbel during the observation period, we recorded it as two separate visits.

Experiment 4. To control for possible handling effects of the umbels, we selected 4I umbels (one umbel per plant) of average diameter and height and compared insect visitation before and after the removal of the DCF. We chose umbels the day before the experiment and marked the base of the plant with a piece of non-adhesive plastic ribbon. We began observations at 10:35 by recording the number of insect visits during one minute per umbel. Immediately after this observation period, we removed the DCF and brushed off arthropods, such as spiders, ants, and hemipterans, from the umbel. Then, about $80 \mathrm{~min}$ later, we again recorded the number of insect visits for another minute starting with the first umbel.

For Experiments I-3, we used generalized linear models with Poisson distribution to examine the effect of the presence of the DCF and umbel height and diameter on the number of insect visits per umbel. For Experiment 4, we used a Sign test to compare the number of visits before and after removal of the DCF on the same umbel. We considered a $P$-value of $\leq$ 0.05 to be statistically significant. Finally, to estimate the prevalence of umbels with DCF in the studied population, we randomly selected and then examined 230 umbels.

\section{RESULTS AND DISCUSSION}

At our study site, beetles (e.g., Dermestidae), flies (e.g., Syrphidae), small bees (e.g., Hylaeus sp., Andrena sp., Lasioglossum spp.) and wasps (e.g., Ichneumonidae) visited umbels of $D$. carota. During the observation period (2.5 min), the number of visits per observation ranged from 0 to $19(\bar{x}$

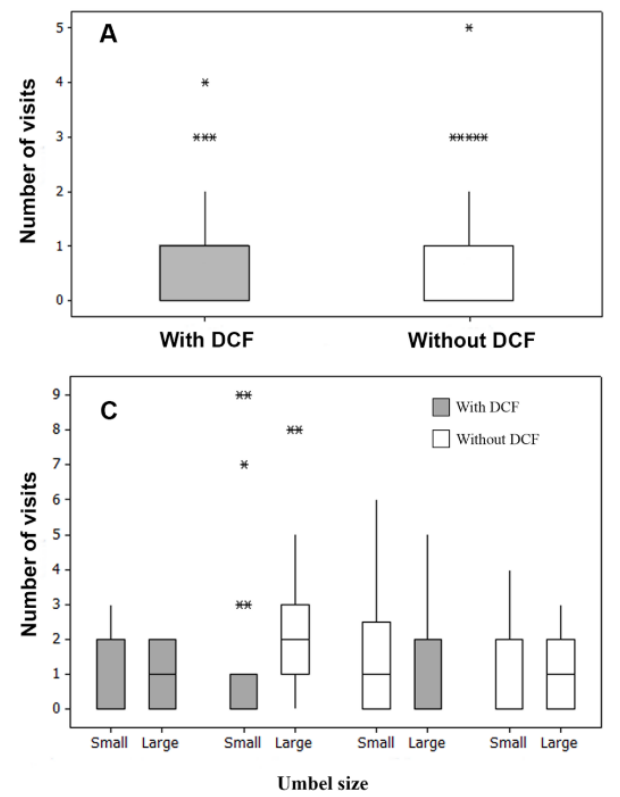

$=1.76 \pm 2.65, N=264)$. The percentage of umbels with a DCF in the studied population was $76.1 \%(N=230)$ and we only observed three umbels with galls in 124 umbels examined $(2.8 \%)$.

In Experiment I, the total number of insect visits between umbels with (control) and without DCF (treatment) were similar, Wald $\chi^{2}=0.346, \mathrm{df}=\mathrm{I}, P=0.557$ (Fig. IA). In Experiment 2, the total number of insect visits differed between heights above and below the population's average height (Wald $\chi^{2}=\mathrm{I} 2.269$, df $=\mathrm{I}, P=0.000$ ), and between the control and treatment (Wald $\chi^{2}=4.670$, df $=\mathrm{I}, P$ $=0.03 \mathrm{I}$ ); however, the interaction between height and presence of DCF was not significant (Wald $\chi^{2}=\mathrm{I} .3 \mathrm{I} 2, \mathrm{df}=$ $\mathrm{I}, P=0.252)$. We recorded a higher number of visits in umbels with the DCF and in umbels placed at $8 \mathrm{I} \mathrm{cm}$ above ground, below population's average (Fig. IB). In Experiment 3 , the total number of insect visits was similar between umbels of small and large diameters (Wald $\chi^{2}=0.623, \mathrm{df}=\mathrm{I}, P$ $=0.430)$ and between the control and treatment (Wald $\chi^{2}=$ $2.502, \mathrm{df}=\mathrm{I}, P=0 . \mathrm{II} 4$ ), but the interaction between umbel size and presence of DCF was significant (Wald $\chi^{2}=4.29 \mathrm{I}$, $\mathrm{df}=\mathrm{I}, P=0.038)$. In Experiment 4, the number of insect visits before and after the DCF was removed from an umbel was similar (Sign test, $\mathrm{Z}=-\mathrm{I} .278, P=0.20 \mathrm{I}, N=4 \mathrm{I}$ ).

Our results suggest context-dependent effects of the DCF, as umbel height influenced the attractiveness of the DCF in the studied population of D. carota. At least one study, using pan-traps, demonstrated that height, even as small as $70 \mathrm{~cm}$ above ground, may play a significant role in the kinds of bees collected, especially in their average body size (Gonzalez et al. 2016). In natural systems, distinctions have even been made between large- and small-bodied bees and the plant
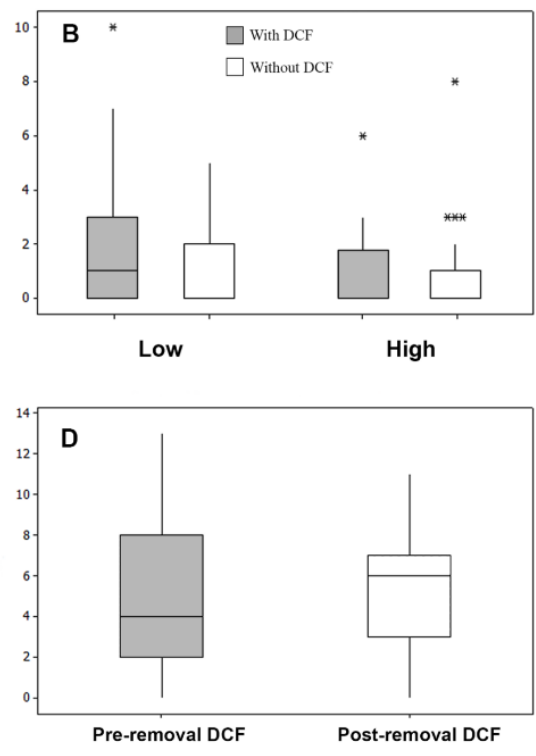

FIGURE I. Number of insect visits recorded from umbels of Daucus carota L with and without the dark central floret (DCF) in Experiments I-4 (A-D, respectively). A = comparison between pairs of umbels of average population's diameter $(10 \mathrm{~cm})$ placed at average population height $(\mathrm{I} 20$ $\mathrm{cm}) . \mathrm{B}=$ comparisons among pairs of umbels of average diameter placed below $(8 \mathrm{I} \mathrm{cm})$ and above $(\mathrm{I} 47 \mathrm{~cm})$ population's average height. $\mathrm{C}=$ comparisons among pairs of umbels of small $(5-7 \mathrm{~cm})$ and large $(\mathrm{II}-\mathrm{I} 3 \mathrm{~cm})$ diameters placed at average population's height. $\mathrm{D}=$ comparison between umbels of average diameter and height before and after the removal of DCF. Boxplots display median, quartiles, and extreme values, the latter indicated by an asterisk. 
communities they forage among (Frankie et al. 1983; Barthell et al. in preparation). These patterns may relate not only to the species-specific characteristics of the bees but the energetics of size in the foraging dynamics of bee species within plant communities (Schaefer et al. 1979).

If bees and other pollinators tend to fly in the horizontal stratum and they are naturally attracted to flowers or inflorescences of taller plants (Gumbert \& Kunze I999; Lortie and Aarssen 1999; Cane et al. 2000), then short umbels likely experience fewer insect visits than tall umbels. Thus, the presence of the DCF in short umbels might increase their attractiveness to potential visitors in this community. We did not assess if the presence of the DCF varies with plant height in our study population. However, anecdotal observations in one coastal population of D. carota at Kalloni Bay, Island of Lesvos, Greece, revealed that the DCF was frequently absent from short umbels ( $<100 \mathrm{~cm}$ above ground), on the same plants having umbels of average or above average height with the DCF. The co-occurrence of umbels with and without the DCF on the same plant suggests that environmental factors (e.g., light intensity, arid conditions, arthropod visitation) and plant developmental factors affect the expression of flower traits (e.g., Gonzáles et al. 2016).

Finally, we cannot refute the hypothesis that the DCF may mediate visitation by certain taxa, as we did not address this aspect in our study. Our conflicting results for umbels at different heights support the hypothesis that DCF function depends on ecological context, reliant on both the visitor community and the predominant flower phenotype (Goulson et al. 2009; Polte \& Reinhold 2013).

\section{ACKNOWLEDGEMENTS}

We are indebted to Jeff Ollerton, Jane Stout, and an anonymous reviewer for comments and suggestions that improved this manuscript. Our colleagues Özge Can Niyaz and Cüneyt Aki from Çanakkale Onsekiz Mart University for their unconditional help and support during our field studies in Turkey. This work was supported by the National Science Foundation's REU program (DBI I560389).

\section{REFERENCES}

Bohart GE, Nye WP (1960) Insect Pollinators of Carrots in Utah. Utah Agricultural Experimental Station Bulletin 4I9:I-I6.

Cane JH, Minckley RL, Kervin LJ (2000) Sampling bees (Hymenoptera: Apiformes) for pollinator community studies: pitfalls of pan-trapping. Journal of the Kansas Entomological Society 73: 225-23I.

Darwin C (1888) The different forms of flowers on plants of the same species, $3^{\text {rd }}$ edn. John Murray, London, UK.

Eisikowitch D (1980) The role of dark flowers in the pollination of certain umbelliferae. Journal of Natural History I4:737-742.

Frankie GW, Haber WA, Opler PA, Bawa KS (I983) Characteristics and organization of the large bee pollination system in the Costa Rican dry forest. In: Jones CE, Little RJ (eds) Handbook of Experimental Pollination Biology. Van NostrandReinhold Company Inc., New York, pp 4 I I-447.

Gonzáles WL, Suarez LH, Gianoli E (2016) Genetic variation in the reduction of attractive floral traits of an annual tarweed in response to drought and apical damage. Journal of Plant Ecology 9:629_ 635.

Gonzalez VH, Park KE, Çakmak I, Hranitz JM, Barthell JF (20I6) Pan traps and bee size in unmanaged urban habitats. Journal of Hymenoptera Research 5I:24I-247.

Goulson D, McGuire K, Munro EE, Adamson S, Colliar L, Park KJ, Tinsley MC, Gilburn AS (2009) Functional significance of the dark central floret of Daucus carota (Apiaceae) L.; is it an insect mimic? Plant Species Biology 24:77-82.

Gumbert A, Kunze J (1999) Inflorescence height affects visitation behavior of bees-A case study of an aquatic plant community in Bolivia. Biotropica 31:466-477.

Lamborn E, Ollerton J (2000) Experimental assessment of the functional morphology of inflorescences of Daucus carota (Apiaceae): testing the 'fly catcher effect'. Functional Ecology I $4: 445-454$

Lortie CJ, Aarssen LW (1999) The advantage of being tall: higher flowers receive more pollen in Verbascum thapsus L. (Scrophulariaceae). Ecoscience 6:68-7I.

Ollerton J, Killick A, Lamborn E, Watts S, Whiston M (2007) Multiple meanings and modes: on the many ways to be a generalist flower. Taxon 56:717-728.

Polte S, Reinhold K (2013) The function of the wild carrot's dark central floret: attract, guide or deter? Plant Species Biology 28:8I86.

Schaffer WM, Jensen DB, Hobbs DE, Gurevitch J, Todd JR, Schaffer VM (1979) Competition, foraging energetics, and the cost of sociality in three species of bees. Ecology 60:976-987.

Thomson JD (1988) Effects of variation in inflorescence size and floral rewards on the visitation rates of traplining pollinators of Aralia hispida. Evolutionary Ecology 2:65-76.

Westmoreland D, Muntan C (1996) The influence of dark central florets on insect attraction and fruit production in Queen Anne's Lace (Daucus carota L.). American Midland Naturalist I35:122I29. 